\title{
Effects of Tail Docking on Milk Quality and Cow Cleanliness ${ }^{1}$
}

\author{
D. A. Schreiner and P. L. Ruegg \\ Department of Dairy Science \\ University of Wisconsin \\ 1675 Observatory Dr. \\ Madison, WI 53706
}

\section{ABSTRACT}

The objective of this study was to determine the effect of tail docking on somatic cell count (SCC), intramammary infection (IMI), and udder and leg cleanliness in commercial dairy herds. Lactating dairy cows $(n=1250)$ from eight Wisconsin farms were blocked by farm and randomly allocated to tail docked (D) or control (C) groups. Milk samples, somatic cell counts, and hygiene scores were collected for 8 to $9 \mathrm{mo}$. The prevalence of IMI was determined for each of the five occasions when milk samples were obtained. Udder and leg cleanliness were assessed during milk sample collection. Docked and control animals were compared by logSCC, prevalence of IMI, and leg and udder cleanliness score. Variables were analyzed according to all treatment, period, and farm interactions. At the end of the study period $76(12.2 \%)$ and $81(13 \%)$ of cows were culled in the $\mathrm{D}$ and $\mathrm{C}$ groups, respectively. There were no significant differences in the initial data for parity, daily milk yield, logSCC, or DIM between treatment groups. Effects significant to farms were identified for all variables over all periods. Period was significant for all variables except for the prevalence of environmental pathogens, but no period $\times$ treatment interactions were detected. There was no significant difference between treatment groups for somatic cell count. The prevalence of contagious, environmental, or minor pathogens did not differ significantly between treatment groups. This study did not identify any differences in udder or leg hygiene or milk quality that could be attributed to tail docking.

(Key words: mastitis, somatic cell count, hygiene, intramammary infection)

Abbreviation key: $\mathbf{C}=$ control, $\mathbf{D}=$ docked.

Received March 4, 2002.

Accepted April 12, 2002.

Corresponding author: Pamela L. Ruegg; email: plruegg@facstaff. wisc.edu.

${ }^{1}$ Funding for this project was provided from the USDA Cooperative State Research, Education and Extension Service project WISO 4384.

\section{INTRODUCTION}

Mastitis continues to be the most frequent and costly disease of dairy cattle, and production losses due to subclinical mastitis on dairy farms in the United States have been estimated to exceed $\$ 1$ billion dollars annually (Ott, 1999). In general, mastitis is classified as either contagious or environmental based on the reservoir and most common route of transmission of the pathogens. The primary reservoir for contagious pathogens is the udder of infected cows, and the primary route of transmission is through contact with contaminated milking equipment, hands of the milking technician, or towels used to clean teats of multiple cows. The most common contagious mastitis pathogens include Staphylococcus aureus and Streptococcus agalactia. The reservoirs for environmental pathogens are water, manure, and dirt present in the environment. Cows often come in contact with environmental mastitis pathogens in their walkways or housing areas. When the teats and udder are allowed to become wet and dirty, large numbers of these bacteria have the opportunity to infect the udder. The most common environmental mastitis pathogens are coliform bacteria (such as Escherichia coli and Klebsiella spp.,) and environmental streptococci (such as Streptococcus uberis and Streptococcus dysgalactia). The risk of infection to the mammary gland is related to the amount of exposure to pathogens and the efficiency of the bovine defense mechanism (Hamann, 1991).

Some farmers use tail docking as a management tool to reduce exposure to potential udder pathogens. The shortening of tails is thought to reduce exposure by eliminating contact between the tail hair and manure present in housing areas. Some also believe that tail docking improves milking hygiene and allows for better preparation of the udder. An Australian study reported that $35 \%$ of Victorian dairy farms routinely docked tails (Barnett et al., 1999). Respondents believed that removal of the tail resulted in faster milking, reduced risks to the operator, and reduced rates of mastitis. These perceived benefits were attributed to improvements in udder hygiene. Premilking udder 


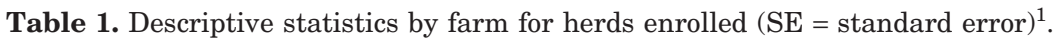

\begin{tabular}{|c|c|c|c|c|c|c|c|c|c|}
\hline \multirow[b]{2}{*}{ ID } & \multirow[b]{2}{*}{ Breed $^{1}$} & \multicolumn{2}{|c|}{$\begin{array}{l}\text { Number } \\
\text { enrolled }\end{array}$} & \multicolumn{2}{|c|}{$\begin{array}{l}\text { Number } \\
\text { culled }\end{array}$} & \multicolumn{4}{|c|}{ Values from first DHI test after enrollment } \\
\hline & & D & $\mathrm{C}$ & D & $\mathrm{C}$ & Milk yield & SCC (x1000) & Parity & DIM \\
\hline 1 & $\mathrm{H}$ & 34 & 33 & 3 & 2 & $21.8(0.7)$ & $121(22)$ & $1.7(0.07)$ & $193(12.5)$ \\
\hline 2 & $\mathrm{H}$ & 36 & 35 & 3 & 9 & $28.0(1.1)$ & $261(136)$ & $1.7(0.08)$ & $169(18.3)$ \\
\hline 3 & $\mathrm{H}$ & 65 & 65 & 11 & 12 & 31.2 & $412(101)$ & $2.3(0.08)$ & $105(12.4)$ \\
\hline 4 & $\mathrm{H}$ & 55 & 55 & 10 & 8 & $30.4(1.0)$ & $319(58)$ & $2.8(0.18)$ & $133(11.0)$ \\
\hline 5 & $\mathrm{H}$ & 89 & 89 & 9 & 11 & $31.0(0.7)$ & $284(50)$ & $3.2(0.13)$ & $147(10.0)$ \\
\hline 6 & $J$ & 92 & 92 & 11 & 10 & $25.0(0.5)$ & $221(39)$ & $2.7(0.13)$ & $124(8.0)$ \\
\hline 7 & $\mathrm{H}$ & 92 & 92 & 13 & 19 & $35.5(1.0)$ & $128(27)$ & $2.6(0.11)$ & $143(10.0)$ \\
\hline 8 & $\mathrm{H}$ & 163 & 163 & 16 & 10 & $27.7(0.8)$ & $324(48)$ & $1.6(0.03)$ & $100(6.0)$ \\
\hline
\end{tabular}

${ }^{1} \mathrm{H}=$ Holstein, $\mathrm{J}=$ Jersey; D = Docked, C = Control.

hygiene is an important determinant of milk quality (Pankey, 1989). Bodoh et al. (1976) indicated that herd management and hygiene had a greater influence on SCC of bulk tank milk than the use of dry cow therapy. Rear quarters have been demonstrated to have higher rates of IMI, and the presence of intact tails was considered as a potential causative factor (McCrory, 1976). Tail hair that becomes contaminated with manure may cross-contaminate the body and udder of the cow (Johnson, 1992). Tucker et al. (2001) monitored 413 animals from a single dairy herd for 2 mo to determine the potential effects of tail docking on cow cleanliness and udder health. They reported no significant effect of tail docking on cow cleanliness or udder health, but the short duration of this study and limited number of cows enrolled in it likely reduced their ability to detect differences between groups. Eicher et al. (2001) used a 5-point cleanliness scoring system to monitor the cleanliness of 16 primiparous Holstein heifers housed in a tie-stall barn in a research herd. In that study, the left rear portions of the docked animals were significantly cleaner than the control animals, but when viewed from behind, the cleanliness scores for udders were not significantly different between docked and control animals. The objective of this study was to determine the effect of tail docking on somatic cell count, intramammary infection, and udder and leg cleanliness in commercial dairy herds.

\section{MATERIALS AND METHODS}

\section{Animals}

Healthy, lactating multiparous and primiparous cows $(\mathrm{n}=1250)$ from eight Wisconsin farms were used in this study (Table 1). The number of lactating cows per herd ranged from 67 to 326. All cows were housed in free-stall housing and were milked in parallel or herringbone parlors. Herds were selected from volun- teers and were eligible to enroll in the study based upon the following criteria: 1) willingness to comply with study protocol; 2) tails of study animals were intact at beginning of study; 3) the herd was enrolled in an official DHIA program; 4) the bulk tank SCC was less than 500,000 cells per $\mathrm{ml}$; and 5) daily milk production exceeded $20 \mathrm{~kg} / \mathrm{cow}$. All housing and management decisions were the responsibility of the farmer. Enrolled animals were housed in appropriate production groups without regard to treatment. Animals that had their tails removed before the study started were excluded from participation. All herds were enrolled between December 2000 and January 2001 and were sampled for 8 to 9 mo. Experimental procedures applied to the animals were according to the recommendations and procedures approved by the Research Animal Resources Center of the UW-Madison (RARC \# A-07-3400-A00976-3-12-99).

\section{Treatment}

All participating cows were vaccinated with two doses of a clostridial vaccine (Bar Vac CD/T, Boehringer Ingelheim, St. Joseph, MO) with the first dose administered a minimum of $21 \mathrm{~d}$ before treatment and the second dose at time of treatment. Animals enrolled in the study were clustered by farm and randomly allocated to either docked (D) or control (C) groups using a table of random numbers. The tails of animals allocated to D were brushed, the hair was clipped, and a rubber castration band was applied approximately $7.6 \mathrm{~cm}$ below the vulva or at the top of the udder, depending on the preference of the farmer. Tails of animals allocated to $\mathrm{C}$ remained intact. The second clostridial vaccine was given on the day of treatment.

\section{Sample Collection and Analysis}

On the day of treatment, before the application of the rubber bands, university personnel collected ster- 
Table 2. Sampling and treatment schedule.

\begin{tabular}{lllll}
\hline & & $\begin{array}{c}\text { Apply } \\
\text { tail } \\
\text { bands }^{1}\end{array}$ & $\begin{array}{c}\text { On-farm } \\
\text { sampling }\end{array}$ & $\begin{array}{c}\text { Download } \\
\text { DHI } \\
\text { data }\end{array}$ \\
\hline Month & Vaccinate & X & X & X \\
Nov. & $\mathrm{X}$ & $\mathrm{X}$ & $\mathrm{X}$ & $\mathrm{X}$ \\
Dec. & $\mathrm{X}$ & $\mathrm{X}$ & $\mathrm{X}$ \\
Jan. & & & $\mathrm{X}$ & $\mathrm{X}$ \\
Feb. & & $\mathrm{X}$ & $\mathrm{X}$ \\
Mar. & & $\mathrm{X}$ & $\mathrm{X}$ \\
Apr. & & $\mathrm{X}$ & $\mathrm{X}$ \\
May & & & $\mathrm{X}$ \\
June & & & $\mathrm{X}$ & \\
July & & & \\
Aug. & & &
\end{tabular}

${ }^{1}$ Application of rubber bands to animals randomly assigned to be docked.

${ }^{2}$ Collection of sterile composite milk samples and hygiene scores of legs and udders; initial sampling date occurred in December or January.

ile composite milk samples from all lactating cows during milking. Additional composite milk samples (n $=4$ ) were collected from each study cow approximately every other month for a 9-mo period between December 2000 and August of 2001 (Table 2). Milk samples were immediately put on ice and stored at $-20^{\circ} \mathrm{C}$ upon arrival at the laboratory. Collection of milk samples and microbiological procedures were performed as outlined by the National Mastitis Council (National Mastitis Council, 1999). In brief, blood agar plates were streaked on one quarter with thawed milk samples using 0.1-ml disposable plastic loops and incubated at $37^{\circ} \mathrm{C}$ for 24 to $48 \mathrm{~h}$. The morphology and hemolysis patterns of bacterial colonies were determined, and significant organisms differentiated, with standard microbiologic methods. Staphylococcus aureus were identified using mannitol and coagulase reactions, Streptococcus spp. were differentiated using the CAMP test, esculin reactions, and agglutination, and gram-negative bacteria were tested using MacConkey agar, motility, indole, and ornithine reactions, and reactions on triple sugar iron slants.

The prevalence of IMI was determined for each of the five sampling dates. Milk samples were coded as "negative" (no growth), "contagious pathogen" (Staphylococcus aureus, Streptococcus agalactia), "environmental pathogen" (Escherichia coli, Klebsiella spp., Streptococcus spp., Enterococcus spp.), "minor pathogen" (coagulase-negative Staphylococcus, Actinomyces spp., Corynebacteria spp.) or "contaminated" (any culture with more than two bacterial species per sample other than Strep. agalactia). All contaminated samples were discarded, and results were not included in statistical analysis. Prevalence was defined as the percentage of sampled animals on each farm infected with a given pathogen for each sample date.
One researcher assessed udder and leg cleanliness scores during the collection of milk samples. Udders and legs were each given a subjective score based upon the following criteria: 1) completely free of dirt or has very little dirt; 2) slightly dirty; 3) mostly covered in dirt; or 4) completely covered, caked on dirt (Figure 1). Somatic cell count data for each farm were downloaded from DHIA each month.

\section{Statistical Analyses}

For the first test after enrollment, T-tests were used to compare the parity, DIM, milk production and log SCC among groups using DHIA data. The prevalence of IMI for contagious (Staphylococcus aureus and Streptococcus agalactia), environmental (E. coli, Klebsiella spp., Streptococcus spp., and Enterococcus spp.) and minor (coagulase-negative Staphylococcus spp., Actinomyces spp., Corynebacteria spp.) mastitis pathogens was compared among groups through use of logistic regression (SAS, 1999). The logistic regression model included these elements: presence of an IMI as a response variable (Yes, No), treatment (docked, control), farm (1 to 8), period (1 to 5), and interactions (period $\times$ farm, period $\times$ treatment, farm $\times$ treatment, and farm $\times$ period $\times$ treatment). Somatic cell counts were transformed with logarithms and compared using PROC MIXED (SAS, 1999). Analysis of this data used a repeated measures model that included: effects of subject (cow nested within farm by treatment), treatment (docked, control), month (1 to 9), farm (1 to 8), first-order interactions, and treatment $\times$ farm $\times$ month. Udder and leg cleanliness scores were treated as class variables and analyzed using PROC MIXED. This analysis utilized a repeated measures model that included: effect of subject (cow), treatment (docked, control), period (1 to 5), and first order interactions. Also, the proportion of animals within each udder and leg class was compared between the two treatments, using chi-square analysis.

\section{RESULTS}

\section{Animals}

The mean (SE) parity and DIM at enrollment for enrolled animals were $2.3(0.04)$ and 114.1 (3.3), respectively. The mean milk yield and SCC at enrollment were $25.7(0.41) \mathrm{kg}$ and $235,636(18,923)$ cells per milliliter, respectively. Animals $(\mathrm{n}=625)$ were assigned to each group at the beginning of the study. At the end of the study period, $76(12.2 \%)$ and 81 (13.0\%) of cows were culled in the D and C groups, respectively. Differences in culling between groups were not significant $(P=0.73)$. There were no signifi- 


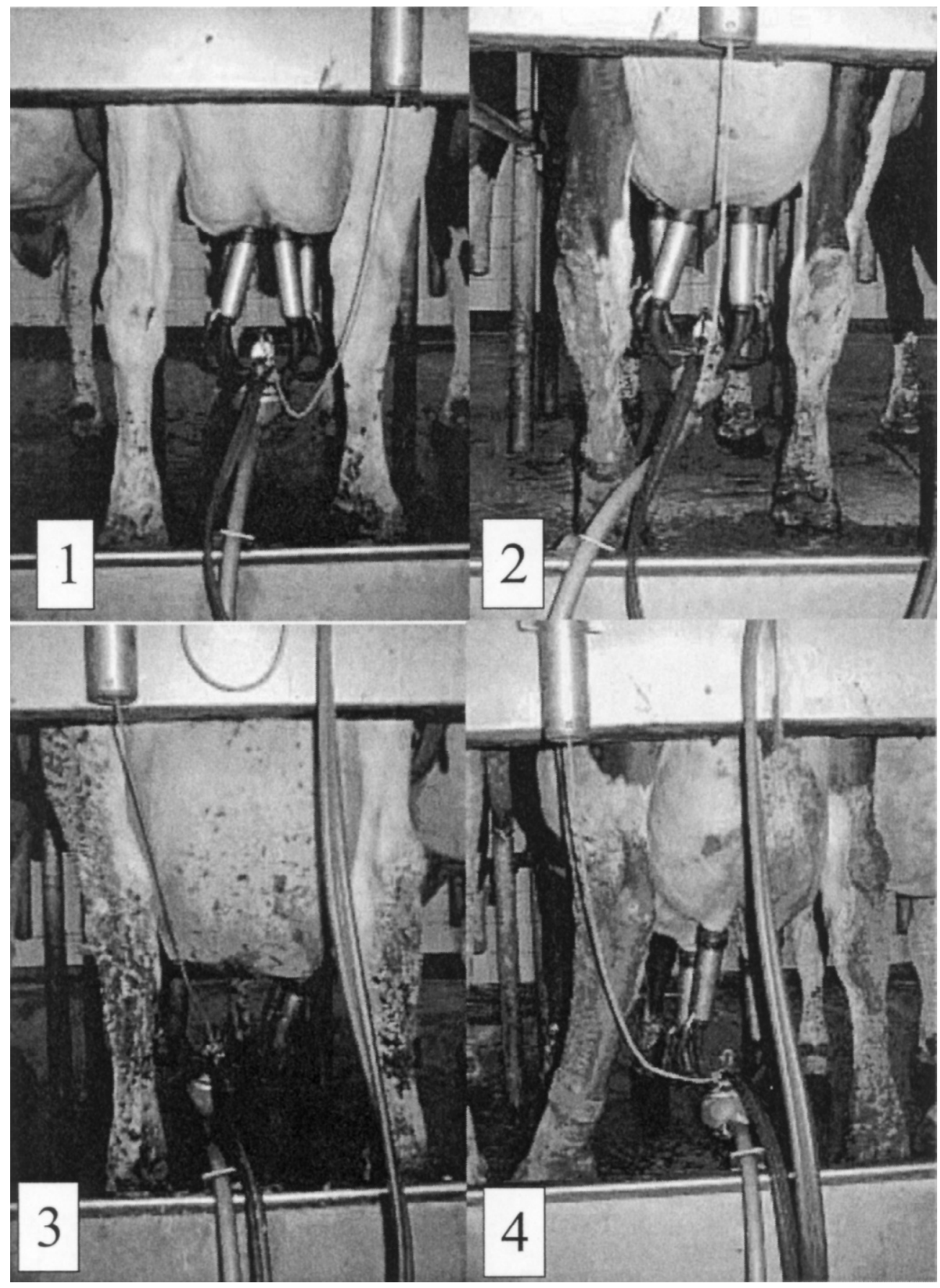

Figure 1. Udder cleanliness score. Picture number corresponds to the score for udder and leg.

cant differences in initial values for parity, daily milk yield, $\operatorname{logSCC}$ or DIM between animals assigned to D or C (Table 3).

\section{Farm Effect}

There were significant differences among farms for all of the variables analyzed over all of the periods.
The prevalence of IMI caused by contagious pathogens was significantly different among farms, ranging from 0 to $21 \%$ of sampled animals $(P<0.001$; Figure 2$)$. The prevalence of environmental pathogens was significantly different among farms, ranging from 3.8 to $17.6 \%$ of sampled animals $(P<0.001$; Figure 2$)$. A large proportion of minor pathogens were recovered from the composite milk samples, and the prevalence 
Table 3. Descriptive statistics by treatment for first DHI test after enrollment.

\begin{tabular}{lrlrll}
\hline & Docked & SE & Control & SE & $P$-value \\
\hline Parity & 2.27 & 0.06 & 2.33 & 0.06 & 0.447 \\
Milk (kg) & 29.07 & 0.49 & 29.10 & 0.49 & 0.694 \\
logSCC & 2.36 & 1.35 & 2.48 & 1.55 & 0.214 \\
DIM & 136.51 & 7.57 & 122.04 & 6.90 & 0.334 \\
\hline
\end{tabular}

of minor pathogens was significantly different between farms (Figure 2; $P<0.001$ ). Log SCC varied significantly among farms $(P<0.001)$; this was expected given the differences in IMI (Table 4). Mean udder and leg cleanliness scores varied significantly $(P<0.01)$ among farms (Table 5$)$.

There were significant differences in parity and DIM among the farms $(P<0.01$; Table 1$)$. Mean DIM varied dramatically amongst the farms and were lower on farms that were in the process of expansion.

\section{SCC}

Log SCC increased approximately 0.15 units (14\%) with time $(P<0.001)$, but no significant differences $(P=0.96)$ between treatment groups were identified (Figure 3).

\section{Prevalence of IMI}

Farm $\times$ treatment interactions were not detected for contagious $(P=0.999)$, environmental $(P=0.67)$,

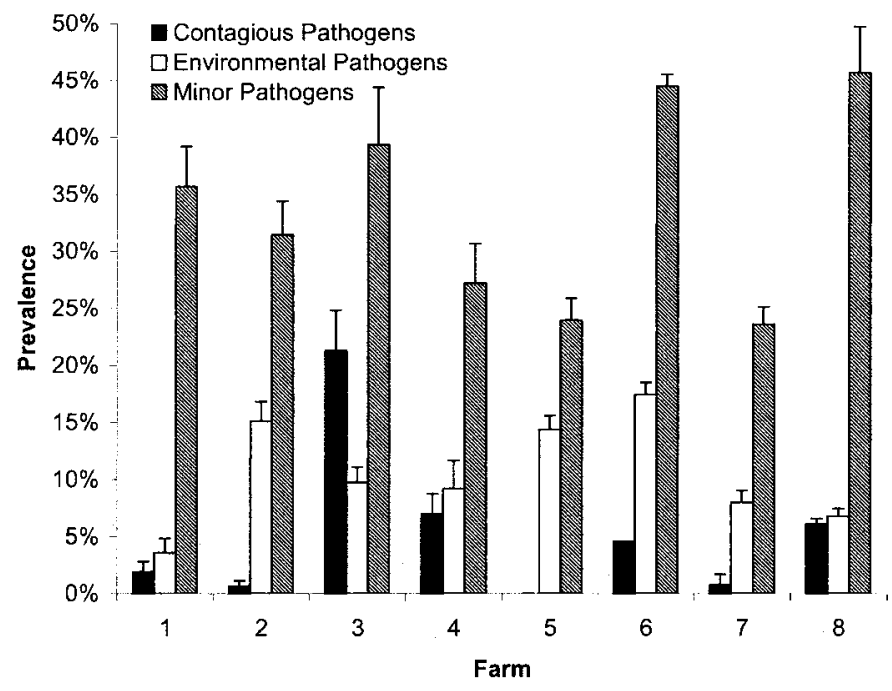

Figure 2. Prevalence of contagious pathogens, ${ }^{1}$ environmental pathogens, ${ }^{2}$ and minor pathogens ${ }^{3}$ by farm. Brackets indicate standard error. ${ }^{1}$ Staphylococcus aureus and Streptococcus agalactia; ${ }^{2}$ Escherichia coli, Klebsiella spp., Streptococcus spp., and Enterococcus spp.; ${ }^{3}$ coagulase-negative Staphylococcus spp., Actinomyces spp., and Corynebacteria spp.
Table 4. LogSCC by farm pooled over all observation periods.

\begin{tabular}{llll}
\hline Farm & LogSCC & SE & $95 \%$ CI \\
\hline 1 & 1.78 & 0.08 & $1.62-1.95$ \\
2 & 1.95 & 0.08 & $1.80-2.10$ \\
3 & 2.41 & 0.06 & $2.29-2.53$ \\
4 & 2.01 & 0.07 & $1.87-2.15$ \\
5 & 1.89 & 0.04 & $1.81-1.97$ \\
6 & 2.13 & 0.04 & $2.05-2.21$ \\
7 & 1.84 & 0.04 & $1.76-1.92$ \\
8 & 2.06 & 0.03 & $2.00-2.12$ \\
\hline
\end{tabular}

or minor pathogens $(P=0.094)$. The prevalence of infection for contagious pathogens was not significantly different $(P=0.111)$ between treatment groups, but the prevalence of IMI caused by contagious pathogens increased over time (Table 6; $P<0.001$ ). The prevalence of IMI caused by environmental pathogens was not significantly different $(P=0.731)$ between groups (Table 6), and no significant period differences $(P=0.172)$ were detected. The prevalence of IMI infection caused by minor pathogens was not significantly different $(P=0.144)$ between groups (Table 6). The prevalence of IMI attributed to minor pathogens decreased with time $(P<0.001)$.

\section{Udder and Leg Cleanliness}

A significant farm $\times$ treatment interaction was identified in the udder and leg cleanliness scores (Table 5; $P<0.003$ ). Udder cleanliness scores were about 0.2 units lower during the initial observation period compared with other observation periods (Figure 4; $P$ $<0.001)$. The proportional distribution of udder cleanliness scores was not significantly associated with treatment $\left(\mathrm{X}^{2}=1.33 ; P=0.722\right)$, and there was no significant difference $(P=0.825)$ in udder cleanliness score between treatments during the period (Figure 4). Leg cleanliness scores in April and June were about 0.25 to 0.40 units lower than scores in other months (Figure 5). During August, leg cleanliness scores for docked animals were significantly lower than the scores of control animals $(P<0.01$; Figure 5$)$. Leg cleanliness scores tended to be lower in docked animals in other periods $(P=0.055)$. The proportional distribution of leg cleanliness scores also tended to be associated with treatment $\left(\mathrm{X}^{2}=7.60 ; P=0.055\right)$.

\section{DISCUSSION}

The farms enrolled in this study were larger than average Wisconsin dairy farms but were reasonably representative of commercial dairy farms that are housed in free stalls. The bulk tank SCC values of the enrolled farms were lower than the 334,000 cells per 
Table 5. Udder and leg cleanliness scores ${ }^{1}$ by farm and treatment.

\begin{tabular}{llllll}
\hline Farm & Score & Docked (SE) & Control (SE) & Difference & $P$-Value \\
\hline \multirow{2}{*}{1} & Udder & $2.01(0.08)$ & $1.74(0.06)$ & +0.27 & 0.009 \\
& Leg & $2.35(0.07)$ & $2.09(0.06)$ & +0.26 & 0.006 \\
2 & Udder & $2.20(0.07)$ & $2.24(0.08)$ & NSD $^{2}$ & 0.708 \\
& Leg & $2.46(0.07)$ & $2.76(0.08)$ & -0.30 & 0.004 \\
& Udder & $2.30(0.05)$ & $2.51(0.06)$ & -0.21 & 0.065 \\
4 & Leg & $2.62(0.05)$ & $2.80(0.05)$ & -0.18 & 0.033 \\
& Udder & $1.94(0.06)$ & $2.01(0.06)$ & NSD & 0.385 \\
5 & Leg & $2.14(0.05)$ & $2.22(0.05)$ & NSD & 0.281 \\
& Udder & $1.88(0.04)$ & $1.96(0.04)$ & NSD & 0.122 \\
6 & Leg & $2.18(0.04)$ & $2.27(0.04)$ & NSD & 0.061 \\
& Udder & $2.35(0.05)$ & $2.21(0.05)$ & +0.14 & 0.020 \\
7 & Leg & $2.30(0.04)$ & $2.28(0.04)$ & NSD & 0.832 \\
& Udder & $1.84(0.04)$ & $1.83(0.04)$ & NSD & 0.959 \\
8 & Leg & $2.11(0.03)$ & $2.15(0.04)$ & NSD & 0.343 \\
& Udder & $2.15(0.03)$ & $2.17(0.03)$ & NSD & 0.513 \\
& Leg & $2.37(0.03)$ & $2.44(0.08)$ & -0.07 & 0.042 \\
\hline
\end{tabular}

${ }^{1}$ Scale range is from 1 (cleanest) to 4 (dirtiest).

${ }^{2}$ No significant difference.

milliliter reported for all Wisconsin farms (Ruegg and Tabone, 2000), indicating that subclinical mastitis was less prevalent in this group of farms. Considerable differences in management existed among farms. For example, only half of the farms routinely forestripped cows before unit attachment making detection of mild clinical mastitis unlikely. The type and age of the milking parlors varied considerably among farms. Management of housing and milking parlors can contribute to exposure to environmental pathogens that may result in IMI and reduced milk quality. In our study, the overall milk quality of the herds enrolled varied by farm, as demonstrated by a significant farm effect for all variables analyzed. We at-

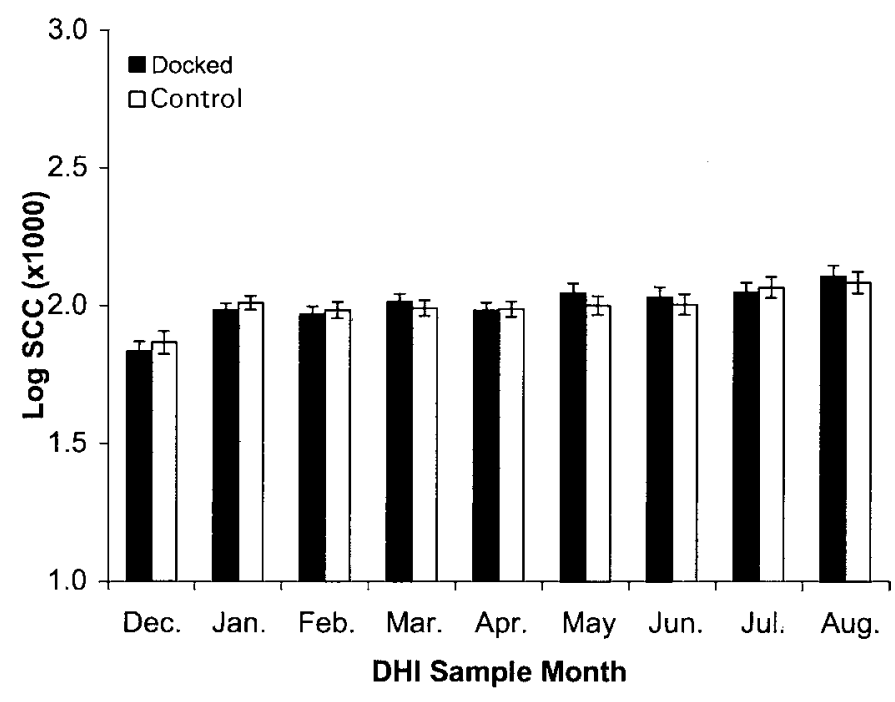

Figure 3. LogSCC by treatment and month. Brackets indicate standard error. tempted to account for variation within the farms by randomly assigning treatments within each.

Period was highly significant for all variables. The prevalence of IMI caused by major pathogens (contagious and environmental isolates) and SCC were significantly higher during the summer months. Seasonal trends in SCC values for Wisconsin dairy herds have been previously reported (Ruegg and Tabone, 2000). Increased SCC values during the summer months are generally attributed to environmental conditions that favor growth of pathogens (Allore et al., 1997). Udder and leg cleanliness varied significantly between periods, which may be attributable to the management of free-stall housing environments.

Composite samples (rather than quarter samples) were obtained because of budgetary constraints. The use of composite samples rather than quarter samples has disadvantages (Lam et al., 1996). Dilution of infected quarter milk with milk from three uninfected quarters increases the likelihood of isolation of bacteria and can potentially result in underestimating the number of IMI. Failing to obtain equal volumes of milk in each sample may affect the culture results by further dilution. Contamination rate increases in composite milk samples, and it is difficult to determine the origin of environmental bacteria such as Streptococci spp., coagulase-negative Staphylococcus spp., and coliforms. We attempted to minimize the contamination rate by having trained researchers collect the milk samples and by using a rigorous definition of contamination, but the high prevalence of coagulase-negative Staphylococcus spp. found in our samples may have been related to our use of composite milk samples. 
Table 6. Prevalence of IMI by treatment and month (SE). ${ }^{1}$

\begin{tabular}{|c|c|c|c|c|c|c|}
\hline & & December & February & April & June & August \\
\hline & & & & $\%(\mathrm{SE})$ & & \\
\hline \multicolumn{7}{|l|}{ Contagious $^{2}$} \\
\hline & Docked & 2.2 & 4.1 (1.8) & $5.7(3.3)$ & $8.1(2.8)$ & $8.6(3.8)$ \\
\hline \multicolumn{7}{|l|}{ Environmental $^{3}$} \\
\hline & Docked & $10.4(3.0)$ & $10.9(2.1)$ & 11.8 & $12.6(2.3)$ & $7.6(2.3)$ \\
\hline & Control & $12.0(2.4)$ & $13.4(2.2)$ & $11.3(1.5)$ & 8.0 & $7.6(1.9)$ \\
\hline & Docked & $38.6(6.8)$ & $38.9(4.0)$ & 35.2 & $28.9(3.1)$ & $24.6(3.9)$ \\
\hline & Control & $39.0(6.1)$ & $39.4(4.4)$ & 36.1 (3.4) & 30.7 (3.7) & $28.0(2.8)$ \\
\hline
\end{tabular}

${ }^{1}$ Columns may sum to $>100 \%$ because of multiple isolates from single samples.

${ }^{2}$ Staphylococcus aureus and Streptococcus agalactia.

${ }^{3}$ Escherichia coli, Klebsiella spp, Streptococcus spp., Enterococcus spp.

${ }^{4}$ Coagulase-negative Staphylococcus spp., Actinomyces spp., Corynebacteria spp.

In a survey reported by Barnett et al. (1999), a majority of dairy farmers believed that removal of the tail resulted in faster milking, reduced operator risk, and reduced rates of mastitis. These perceived benefits were attributed to improved udder hygiene. Our study was unable to confirm these perceptions. Tail docking is alleged to improve the hygiene of the animal by reducing its exposure to environmental bacteria present in mud and manure on the animal's hide and tail. Evaluation of clinical mastitis caused by environmental pathogens may be a more valid indicator of the potential benefit of tail docking compared with subclinical infections. Accurate detection and recording of clinical mastitis is necessary to establish an estimate of environmental mastitis. We attempted to collect milk samples and data regarding clinical mastitis, but inconsistency in both farm records and

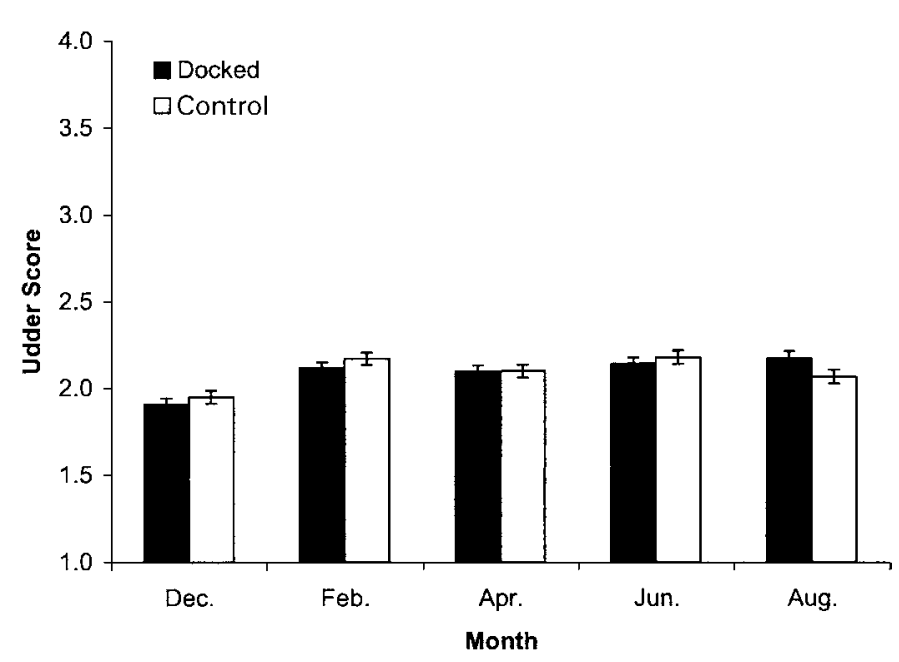

Figure 4. Udder cleanliness score by treatment. Brackets indicate standard error. Scale range is from 1 to 4 with 1 considered cleanest and 4 considered dirtiest. cooperation of milking staff precluded the use of those data.

Tucker et al. (2001) evaluated the effect of tail docking on cow cleanliness and SCC in a single herd over an 8-wk period. They concluded that cow cleanliness did not improve when animals had their tails removed. The relatively small sample size and short observation period in their study increased the probability of a Type II error. Nevertheless, our study is consistent with their results. We assessed the potential effect of tail docking on udder and leg cleanliness by using a subjective scoring system based upon observation of the rear legs and rear udder of the cow. Similar systems have been used to assess the hygiene of cows and facilities (Bartlett et al.; 1992, Barkema et al., 1998). To reduce any potential error associated

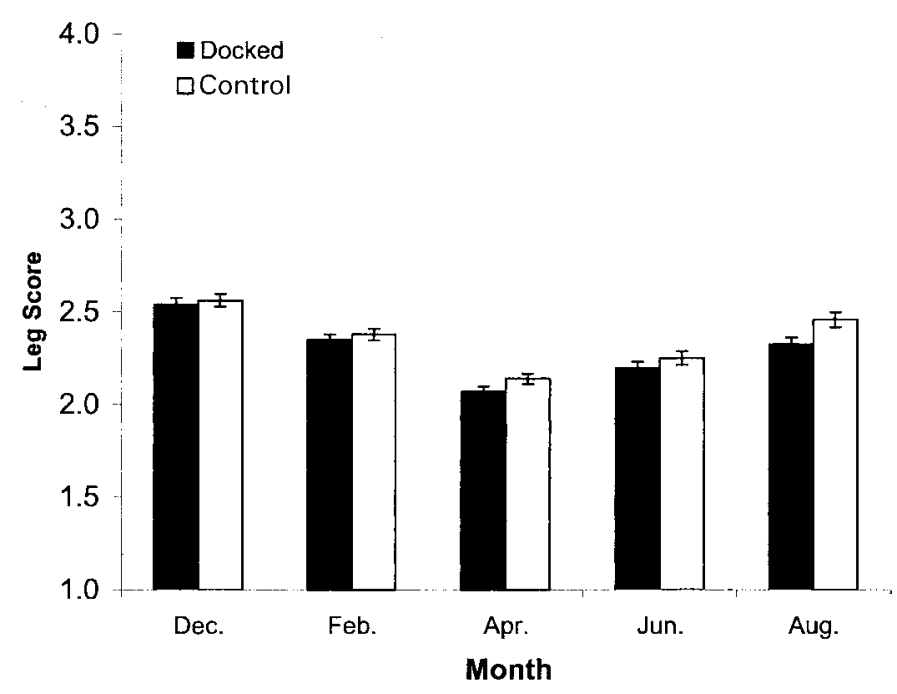

Figure 5. Leg cleanliness score by treatment. Brackets indicate standard error. Scale range is from 1 to 4 with 1 considered cleanest and 4 considered dirtiest. 
with the scoring system, one observer performed all cleanliness scoring. No formal assessment of intraobserver reliability was made; furthermore, the lack of tails on cows in the treatment group made it impossible to blind the observer to treatment. Therefore, some scores could have been influenced by treatment, and some variation in scores may have resulted from inconsistent observations. The large number of observations included in our study should have allowed the detection of relatively small differences in cleanliness scores. Our study identified a significant farm $\times$ treatment interaction for udder and leg cleanliness scores. Tail docking made no consistent difference in animal cleanliness. While some cleanliness scores were statistically related to tail docking, the biological significance of this finding is doubtful because of the small differences between the scores. Eicher et al. (2001) reported that the left rear portion of the body of docked cows housed in tie stalls was cleaner than control animals but were unable to identify a significant difference in udder cleanliness scores. The 16 research animals included in that study were thoroughly cleaned before observation, whereas the animals included in our study were typical of animals housed in commercial dairy farms. The animals included in our study were housed together in free stalls, and it is possible that contact with tails from control animals could have affected the cleanliness of docked animals. Additional research is needed to determine if specific farm situations would benefit from tail docking. Proper premilking management may be able to compensate for a dirty environment by adequately cleaning the udder before application of the milking unit (Guterbock, 1984).

Tucker et al. (2001) concluded that there was no significant difference in SCC between docked and control animals for the months of December and February. Our study agreed with their conclusions and found no significant effect of tail removal on SCC. Log SCC values were nearly identical between groups.

No previous reports of the effect of tail docking on the rate of IMI have been published. The rate of IMI observed in our study was similar to previous reports (Smith et al., 1985; Hogan et al., 1988). The prevalence of IMI caused by Staph aureus was $21 \%$ for one participating herd, but potential confounding effects were accounted for by blocking treatments within farm.

Our study was unable to identify a significant improvement in cow cleanliness or milk quality that could be attributed to tail docking. The among-farm variation in many outcome variables indicates that other management decisions may play a more significant role in determining milk quality. Studies have indicated that there are minimal adverse effects from docking tails of dairy cattle (Petrie et al., 1995; Petrie et al., 1996; Eicher et al., 2000; Tom et al., 2002; Schreiner and Ruegg, accepted), but no positive benefits to the cows have been identified.

\section{REFERENCES}

Allore, H. G., P. A. Oltenacu, and H. N. Erb. 1997. Effects of season, herd size, and geographic region on the composition and quality of milk in the Northeast. J. Dairy Sci. 80:3040-3049.

Barkema, H. W., Y. H. Schukken, T. J. G. M. Lam, M. L. Beiboer, G. Benedictus, and A. Brand. 1998. Management practices associated with low, medium, and high somatic cell counts in bulk milk. J. Dairy Sci. 81:1917-1927.

Barnett, J. L., G. J. Coleman, P. H. Hemsworth, E. A. Newman, S. Fewings-Hall, and C. Zini. 1999. Tail docking and beliefs about the practice in the Victorian dairy industry. Aust. Vet. Journ. 11:742-747.

Bartlett, P. C., G. Y. Miller, S. E. Lance, and L. E. Heider. 1992. Managerial determinants of intramammary coliform and environmental streptococci infections in Ohio dairy herds. J. Dairy Sci. 75:1241-1252.

Bodoh, G. W., W. J. Battista, and L. H. Schultz. 1976. Variation in somatic cell counts in Dairy Herd Improvement milk samples. J. Dairy Sci. 59:1119-1123.

Eicher, S. D., J. L. Morrow-Tesch, J. L. Albright, J. W. Dailey, C. R. Young, and L. H. Stanker. 2000. Tail-docking influences on behavioral, immunological, and endocrine responses in dairy heifers. J. Dairy Sci. 83:1456-1462.

Eicher, S. D., J. L. Morrow-Tesch, J. L. Albright, and R. W. Williams. 2001. Tail-docking alters fly numbers, fly avoidance behaviors, and cleanliness, but not physiological measures. J. Dairy Sci. $84: 1822-1828$

Guterbock, W. M. 1984. Practical aspects of mastitis control in large dairy herds. Part II. Milking hygiene. Comp Con. Edu. Prac. Vet. 6:S651-S658.

Hamann J. 1991. Milking hygiene, milking and mastitis. Dairy Food Env. San. 11:260-264.

Hogan, J. S., K. L. Smith, D. A. Todhunter, and P. S. Schoenberger 1988. Rate of environmental mastitis in quarters infected with Corynebacterium bovis and Staphylococcus aureus. J. Dairy Sci. 71:2520-2525.

Johnson, A. P. 1992. Mastitis control without a slap in the face. Page 146 in Proc. 24th Ann. Conv. Am. Assoc. Bov. Prac. 1991, Orlando, FL.

Lam, T. J. G. M., L. A. van Wuijckhuise, P. Franken, M. L. Morselt, E. G. Hartman, and Y. H. Schukken. 1996. Use of composite milk samples for diagnosis of $S$. aureus mastitis in dairy cattle. J. Am. Vet. Med. Assoc. 208:1705-1708.

McCrory, J. 1976. Do cows' tails help to cause mastitis? J. Ag. $74: 341$.

National Mastitis Council. 1999. Laboratory handbook on bovine mastitis. Natl. Mastitis Counc., Inc., Madison, WI.

Ott, S. 1999. Costs of herd-level production losses associated with subclinical mastitis in US Dairy Cows. Pages 152-156 in Proc. 38th Annu. meeting of Natl. Mastitis Coun., Arlington VA. Natl. Mast. Counc. Inc., Madison, WI.

Pankey, J. W. 1989. Premilking udder hygiene. J. Dairy Sci. 72:1308-1312.

Petrie, N. J., D. J. Mellor, K. J. Stafford, R. A. Bruce, and R. N. Ward. 1996. Cortisol responses of calves to two methods of tail docking used with or without local anaesthetic. N. Z. Vet. J. 44: 4-8.

Petrie, N. J., K. J. Stafford, D. J. Mellor, R. A. Bruce, and R. N. Ward. 1995. The behaviour of calves tail docked with a rubber ring used with or without local anesthesia. N. Z. Soc. An. Prod. 55:58-60.

Ruegg, P. L., and T. J. Tabone. 2000. The relationship between antibiotic residue violations and somatic cell counts in Wisconsin dairy herds. J. Dairy Sci. 83:2805-2809. 
Schreiner, D. A., and P. L. Ruegg. Responses to tail docking in calves and heifers. J. Dairy Sci. (Accepted).

SAS User's Guide: Statistics, Version 8 Edition. 1999. SAS Inst., Inc., Cary, NC.

Smith, K. L., D. A. Todhunter, and P. S. Schoenberger. 1985. Symposium: Environmental effects on cow health and performance. J. Dairy Sci. 68:1531-1553.
Tom, E. M., J. Rushen, I. J. H. Duncan, and A. M. de Passille. 2002. Behavioural, health and cortisol responses of young calves to tail docking using a rubber ring or docking iron. Can. J. Anim. Sci. 82:1-9.

Tucker, C. B., D. Fraser, and D. M. Weary. 2001. Tail docking cattle: effects on cow cleanliness and udder health. J. Dairy Sci. $84: 84-87$. 